\title{
Time-Series Characteristics of Wind Power and Its Impact on Jilin Power Grid
}

\author{
Yanping Xu1, Yong Sun², Taiyi Zheng², Hongyi Cai², Peng Li1, Shuo Ma1 \\ ${ }^{1}$ China Electric Power Research Institute, Beijing, China \\ ${ }^{2}$ Sate Grid Jilin Electric Power Co. Ltd., Changchun, China \\ Email: xuyanping@epri.sgcc.com.cn
}

Received January 2014

\begin{abstract}
With the rapid development of wind power, the large-scale wind power integration brings a new range of issues in dispatching operation. In order to gain a better grasp of the influence caused by wind power combined to the grid, the paper first establishes the impact characteristic indexes, and then analyzes the regularity of wind power time series in different spatial and temporal scales. At last, according to the analysis results, this paper assesses the impact of time-series characteristics of wind power on power grid, such as the frequency regulation, peak load regulation, which can provide the reference for wind power optimal dispatching of Jilin Power Grid.
\end{abstract}

\section{Keywords}

\section{Characteristic Index; Time-Series Characteristics; Frequency Regulation; Peak Load Regulation}

\section{Introduction}

There were about 29 wind farms integrated to power grid by the end of 2012 in Jilin, amounting to 3.3GW, making up $17.06 \%$ of the total installed power capacity within province. The total annual energy production of wind power is $4391 \mathrm{GWh}$, growing by an annualized rate of $10.1 \%$, accounted for $7.17 \%$ of the total annual energy production. Wind power has become the second-largest power source directly controlled by provincial dispatching center.

With the rapid and continuous development of wind power, its randomness and intermittence has brought a series of problems on the operation of grid and increased the difficulty of power system planning and dispatching [1-3]; On the other hand, owing to the statistical regularities of wind power time series in different spacetime scales, if the regularities can be understood profoundly, it will be helpful to grasp the influence caused by wind power. In [4-6], the characteristics of wind power in Northeast China, Gansu and Jiangsu coastal area were analyzed, the impact of wind power on the grid's stability, frequency regulation and peak load regulation was explored. In [7], based on the measured wind power data in North China, at different space-time scales, the statistical regularities of wind power fluctuation were studied from correlation and smoothness by mathematical methods (such as statistical analysis and fitting). In [8], based on wind power historic data for 2 years in Inner Mongolia, fluctuation characteristics of wind power were analyzed by the methods of probability statistics and time series analysis. And the influences of different capacity values of wind power connected to power grid on 
active power balance were explored by simulation experiment.

The above papers analyzed the characteristics of wind power in different ways, but these related researches are non-systematical, not fully reflecting the impact of wind power on power grid. Recently, wind power is developing rapidly in Jilin, but it is studied by very few papers. In view of the situation described above, this paper comprehensively analyzes regularity of wind power time series, firstly establishes the impact characteristic indexes, and then analyzes the regularity of wind power time series at different spatial and temporal scales. At last, according to analysis results, this paper assesses the impact of wind power on power grid, which can provide a reliable basis for perfecting dispatching plan, and can provide the reference and guide for wind power long-term planning and can coordinate development between wind power and power grid.

\section{Study on Time-Series Characteristic Indexes of Wind Power}

The paper studies wind power time series from the characteristics of probability distribution, volatility and correlation, then develops characteristic indexes for multi-perspective reflecting the impact of wind power on dispatching and operation of power system.

Wind power is random and volatility. By studying the probability distribution characteristics of wind power, we can grasp the range and frequency distribution of active output of different wind farms, which can be used in the optimal planning design of power system, and the quantitative study on investment benefit of wind power delivery, can be used in directing and optimizing dispatching and operation, especially when dispatching in a long time scale, such as year, season and month.

By the time scale, wind power fluctuation is divided into the fluctuation of second, minute and hour; According to the spatial scale, it is divided into the fluctuation of active output of a single turbine, wind farms cluster and regional wind farms, etc. Wind power volatility directly relates to space-time scale. If the space-time scale is different, so is the corresponding application scope: from second fluctuation to minutely fluctuation mainly affects the primary and secondary frequency modulation, which can provide a reference for choosing frequency modulation unit; hourly fluctuation, mainly influences real-time scheduling or making dispatching plan.

The correlation between active outputs of wind farms reflects acceptable capacity of power grid for wind power. The correlation between wind power and load reflects the influence degree of peak-valley difference before and after wind power access to power system, and also is a reflection of peak regulation capacity which is required by wind power, can provide a reference for reasonable configuration of reserve capacity.

\subsection{The Probability Distribution Characteristics of Wind Power}

The key index of probability distribution characteristics is to measure power supply capability of wind power. In paper, the primary indexes as follows.

1) The ratio (availability) of wind power $\eta \%$ : The real measured active power account for as a percentage of the rated wind power, that is,

$$
\eta \%=P_{r}(t) / P_{N}
$$

where $P_{r}(t)$ is active output of the $r$ th wind farm at $t$ th moment; $P_{N}$ is rated power of the $r$ th wind farm.

2) The probability distribution is the probabilities of wind power appear at different output levels. $P_{i}$ is the $i$ th level of wind power, normally expressed as $\left[P_{i M i n}, P_{i M a x}\right] ; F_{p i}$ is the probability of the $i$ th output level.

$$
F_{P i}=\frac{N_{\left(P_{\text {Min }} \leq P_{i}<P_{\text {iMax }}\right)}}{N_{\text {total }}} \times 100 \%
$$

where $N_{\left(P_{\text {Min }} \leq P_{i}<P_{\text {iMax }}\right)}$ is the number of the wind power time series in $\left[P_{\text {iMin }}, P_{i M a x}\right], N_{\text {total }}$ is the total number of the wind power time series.

3) The wind power credible capacity[9-10], referring to conventional unit capacity that can be replaced by wind power, which can provide the reference for power balance calculation, reserve selection, reliability analysis in electric power planning. Set $P_{r}$ as conventional unit capacity, $P_{w}$ as wind power capacity, $P_{v}$ as the capacity of equivalent unit which the reliability is the same as conventional unit. $R_{x}$ is a certain reliability index of power system which the installed capacity is $x$.

$$
R_{P_{r}+P_{v}}=R_{P_{r}+P_{w}}
$$


Then the wind power credible capacity is $P_{v}$ in power system of installed capacity is $P_{w}$.

\subsection{The Volatility Characteristics of Wind Power}

Volatility is the most typical nature of wind power, wind power volatility in different situations can be used as a reference for frequency regulation, peak shaving and operational control methods. In paper, its primary indexes as follows.

The wind power volatility is the difference between the highest and the lowest wind power values with $\mathrm{T}$ time range. If the highest begins after the lowest, the difference is positive, also the volatility is positive. If the highest begins before the lowest, the difference is negative, also the volatility is negative.

The wind power volatility is as the equation below shows,

$$
\rho \%=\left\{\begin{array}{l}
\frac{P_{t \max }-P_{t \min }}{P_{N}} \times 100 \%, t_{p_{t \max }}>t_{p_{t \min }} \\
\frac{P_{t \min }-P_{t \max }}{P_{N}} \times 100 \%, t_{p_{t \min }}>t_{p_{t \max }}
\end{array}\right.
$$

where $p_{\text {tmax }}=\operatorname{Max}\left\{p_{t+i}\right\}, \quad p_{\operatorname{tmin}}=\operatorname{Min}\left\{p_{t+i}\right\}, \quad i=0,1,2, \cdots, T / \Delta t-1, \Delta t$ is timescale. $t_{p_{\text {tmax }}}, t_{p_{\text {tmin }}}$ refers to the lengths of time, the difference between the time which $p_{\text {tmax }}, p_{\text {tmin }}$ show up and the initial time.

Adopt "sliding window method" to compute volatility probability distribution of wind power. Firstly, $n$ is the total series length, $T$ is time window, $t$ is sliding step, and then calculated all the volatility within time $T$. If the result of calculation is $\left(\rho_{T_{0} \max }, \rho_{T_{1} \max }, \ldots . . . ., \rho_{T_{(n-T) / t} \max }\right)$, and at last, perform probability statistics for the volatility according to equation (2).

The volatility of wind power in load climbing and lowering period is studied. When the load is in climbing or lowering period, the output power of conventional unit should keep up with the changes in load. The positive/negative fluctuation of wind power has an impact on frequency regulation, and seriously it can cause a significant accident, such as, over-limit frequency and system collapsed. So the research of wind power volatility in load climbing and lowering period can provide a reliable basis for making a plan of frequency regulation and allocating the task of frequency regulation.

The volatility of wind power is also studied in different processes of wind power. With wind power is of similar repeatability every year, it is divided into three processes( Lower power process, small fluctuation process, large fluctuation process) because of the lengths of wind power time series is not enough long [11,12]. By studying the frequency distribution of volatility in different process, we can have a qualitative analysis of the characteristics of the fluctuation.

\subsection{The Correction Characteristics of Wind Power}

The correlation between active outputs of wind farms can be expressed not only correlation but generation simultaneity factor, reflected acceptable capacity of power grid for wind power. The correlation between wind power and load reflects the influence degree of peak-valley difference before and after wind power access to power system.

1) The correlation coefficient is an index which can reflect the correlation between active outputs of two wind farms in a certain area. For example, the correlation coefficient between the active outputs of wind farm A and wind farm $B$ is as the equation below shows,

$$
r=\frac{\sum_{i=1}^{N}\left(P_{A i}-\bar{P}_{A}\right)\left(P_{B i}-\bar{P}_{B}\right)}{\sqrt{\sum_{i=1}^{N}\left(P_{A i}-\bar{P}_{A}\right)^{2}} \sqrt{\sum_{i=1}^{N}\left(P_{B i}-\bar{P}_{B}\right)^{2}}}
$$

For a long statistical period, such as month and year, the probability distribution of correlation can be statistical calculated.

2) The simultaneity factor is the numeric equivalent of the sum of wind power account for as a percentage of the sum of installed capacity of wind power. The simultaneity factor $R(t)$ at time $t$ is as follows. 


$$
R(t)=\frac{\sum_{i=1}^{N_{w}} P_{i}(t)}{\sum_{i=1}^{N_{w}} S_{w i}} \times 100 \%
$$

where $P_{i}(t)$ refers to active output of the $i$ th wind farm at time $t, S_{w i}$ is the installed capacity, $N_{w}$ is the number of wind farms. By studying simultaneity factor in a certain area, how difficult the acceptance of the power system for wind power can be evaluated.

The index of modulating load peak refers to the change in the peak-valley difference between equivalent load and original load, equivalent load can be calculated by taking wind power as negative load. Set the load is $P_{l i}$ within a day, wind power is $P_{w i}, i=1,2,3, \cdots, 24 * 60 / \Delta \mathrm{t}$, the change $\hat{P}$ of the peak-valley difference between equivalent load and original load is as the Equation (7).

$$
\hat{P}=\operatorname{Max}\left\{P_{l i}-P_{w i}\right\}-\operatorname{Min}\left\{P_{l i}-P_{w i}\right\}-\operatorname{Max}\left\{P_{l i}\right\}+\operatorname{Min}\left\{P_{l i}\right\}
$$

If $\hat{P}$ is positive, the peak-valley difference of equivalent load is greater than original load's, otherwise the peak-valley difference of equivalent load is less than original load's. By studying probability distribution of the peak-valley difference, the impact of wind power on peak-load regulation can be measured and the acceptable capacity of power grid for wind power can be judged.

\section{Analysis on the Characteristics of Wind Power Time Series in Jilin}

Bases on the active outputs of 20 wind farms in Jilin to analyze the regularity of wind power. The sampling interval is 15 min. The wind farms in Jilin are divided by geographical area into three wind farm groups, Baicheng, Songyuan and Siping, their installed capacity respectively account for $56.8 \%, 31.4 \%, 11.8 \%$ of the total installed capacity of wind farms that are statistical analyzed in the paper.

\subsection{Probability Distribution Characteristics of Wind Power in Jilin}

Figure 1 shows average daily wind power and average monthly wind power profiles for a year in Jilin. As you can see from Figure 1, average daily wind power is mainly concentrated on $0 \%-40 \%$ of the rated capacity of wind power. Average daily wind power appears a big jump in the adjacent day, and also appears high output for days and low output for days.

Figure 2 presents monthly utilization hours and monthly maximum value of wind power for a year. From the figure we can see, the distribution of monthly utilization hours during the year has some differences, the utilization hours of April, May, October and November are relatively the most, more than 180 hours, but the utilization hours of July and August is the lowest, only $60 \mathrm{~h}-90 \mathrm{~h}$. Wind power in Jilin has obviously seasonal characteristic, Wind in Spring (March to May) and Autumn (September to November), monthly utilization hours are the highest, Winter's (December, January and February) comes second and Summer's is the lowest.

For making the further quantitative analysis for the probability distribution of wind power, Figure $\mathbf{3}$ gives

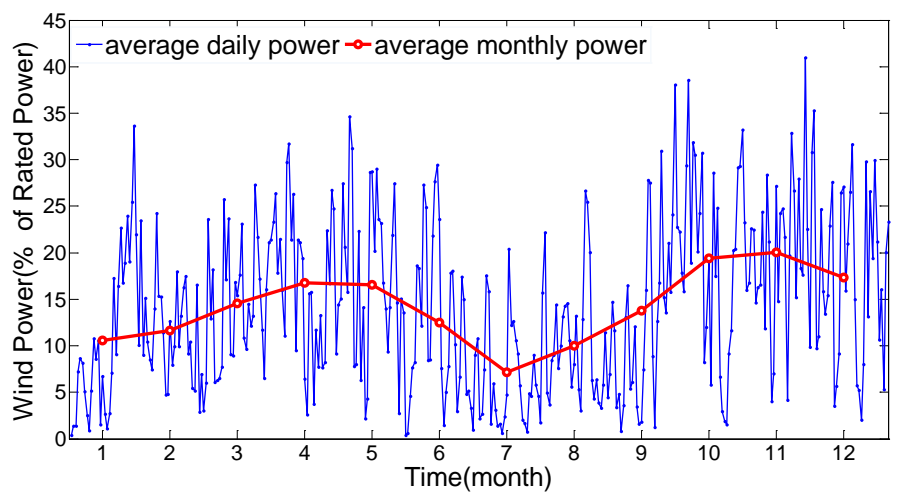

Figure 1. Average daily power and monthly output power of wind power for a year in Jilin. 


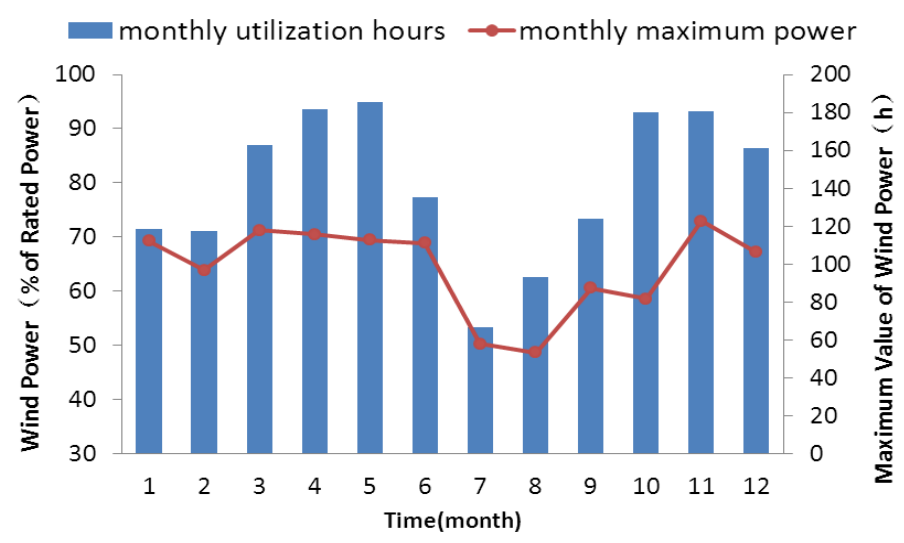

Figure 2. The monthly utilization hours and maximum value of wind power for a year in Jilin.

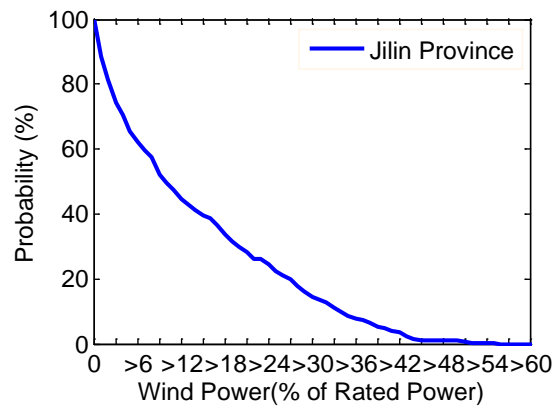

Figure 3. The cumulative probability distribution of wind power in high-load period.

cumulative probability distribution of wind power in high-load period, the wind power credible capacity is related to the ratio of wind power, the figure shows that under the $95 \%$ confidence level, the wind power credible capacity is less than $3 \%$ of the rated capacity. So it means that the capacity that wind power in Jilin can be sure to provide is really low in high-load period.

\subsection{The Volatility Characteristics of Wind Power in Jilin}

The volatility approximate probability distribution of wind power in different time scales and the cumulative probability distribution of wind power in different spatial scales are showed in Figures $\mathbf{4}$ and $\mathbf{5}$ respectively. From Figure 4 we can know the probability that the volatility in $-3 \%$ - 3\% is $95.76 \%$ in 15 min. The probability is $69.76 \%$ in $1 \mathrm{~h}, 15.95 \%$ in $4 \mathrm{~h}$ and $0 \%$ in $24 \mathrm{~h}$; The probability that the volatility in $-3 \%-3 \%$ is the highest in $15 \mathrm{~min}$ and in $1 \mathrm{~h}$. In $4 \mathrm{~h}$, the highest probability is $10.54 \%$ and $11.48 \%$ which the volatility is in $-9 \%--12 \%$ and $0 \%-3 \%$ respectively. In $24 \mathrm{~h}$, the highest probability is $8.94 \%$ and $7.40 \%$ which the volatility is in $-27 \%$ $-30 \%$ and $-33 \% \%--36 \%$ respectively. And along with the increase of timescale, the fluctuation probability distribution transformed from "narrow and high" into "wide and short", that is, the fluctuation is exacerbated. The appearing probabilities of the positive fluctuation and the negative fluctuation are about the same.

As you can see from Figure 5, the probability of the volatility of single wind farm more than $1 \%$ is $60 \%$ in $15 \mathrm{~min}$. In the same case, the probability of Baicheng and Jilin is $34 \%$ and $27 \%$. As the statistic region increased, the smoothness of wind power increased and the volatility decreased.

Figure 6 is the cumulative probability distribution of wind power volatility in $15 \mathrm{~min}$ and the cumulative probability distribution of duration in different wind power output process. From Figure 6(a), the duration of large fluctuation process of wind power, small fluctuation process, low power process are respectively in the range of $24 \mathrm{~h}-204 \mathrm{~h}, 0-108 \mathrm{~h}$ and 0 - $48 \mathrm{~h}$. The probability of duration of the large fluctuation process more than $24 \mathrm{~h}$ is $100 \%$ and the corresponding probability of small fluctuation process and low power process are $20.73 \%$ and $16.26 \%$. From $6(\mathrm{~b})$, the probability of the volatility of large fluctuation more than $1 \%$ is $37.67 \%$, 


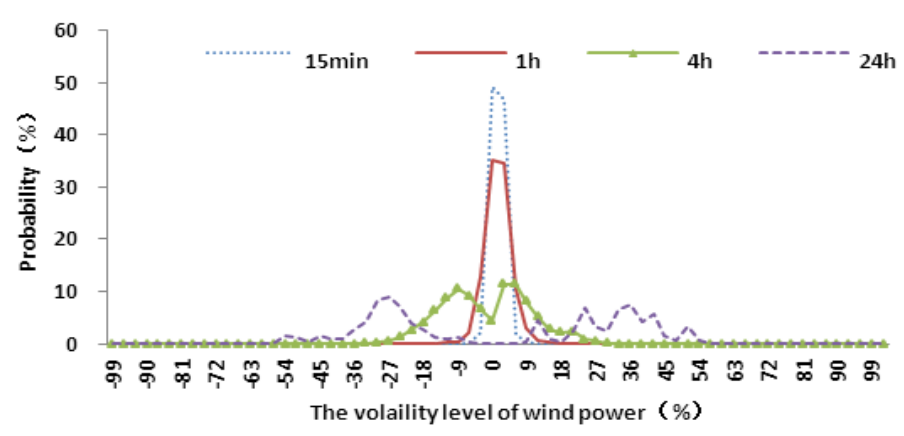

Figure 4. The probability distribution of wind power volatility in Jilin.

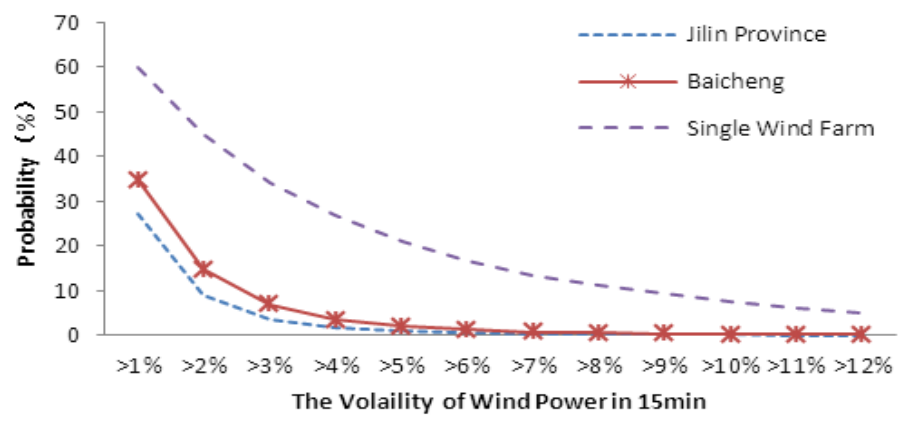

Figure 5. The cumulative probability distribution of wind power volatility in $15 \mathrm{~min}$.

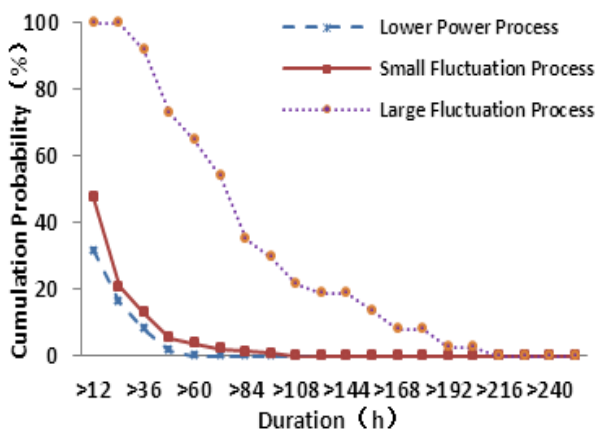

(a)

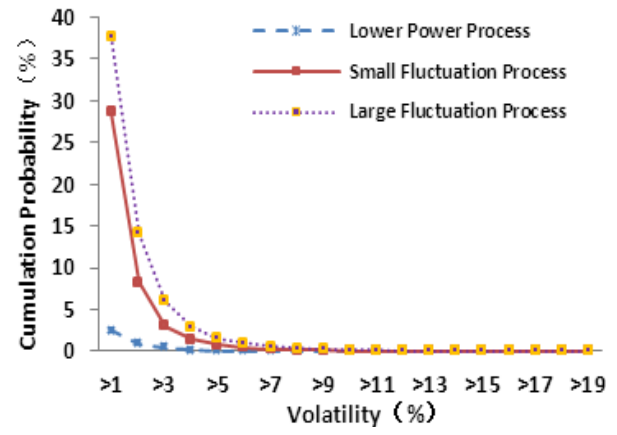

(b)

Figure 6. The cumulative probability distribution of wind power volatility in $15 \mathrm{~min}$ and duration in different wind power output process. (a) The duration; (b) The volatility.

and the corresponding probability of small fluctuation process and low power process are $28.60 \%$ and $2.54 \%$ respectively.

In order to evaluate the extent of wind power fluctuation tracking the variation of load, Figure 7 gives the probabilities of wind power negative/positive fluctuation appeared in load climbing/lowering period in each month. From the figure we can know that the probabilities are both about 50\%, In May, the probability of wind power negative fluctuation appeared is bigger than the probability of wind power positive fluctuation appeared in the load climbing period. In March, June and October, the probability of wind power positive fluctuation appeared is bigger than the probability of wind power negative fluctuation appeared in the load lowering period. In each month, the probability of wind power positive fluctuation appeared in the load lowering period is bigger the probability of wind power negative fluctuation appeared in the load climbing period

\subsection{The Correction Characteristics of Wind Power in Jilin}

The correlation coefficient between the active outputs of different wind farms can reflect whether the changing 


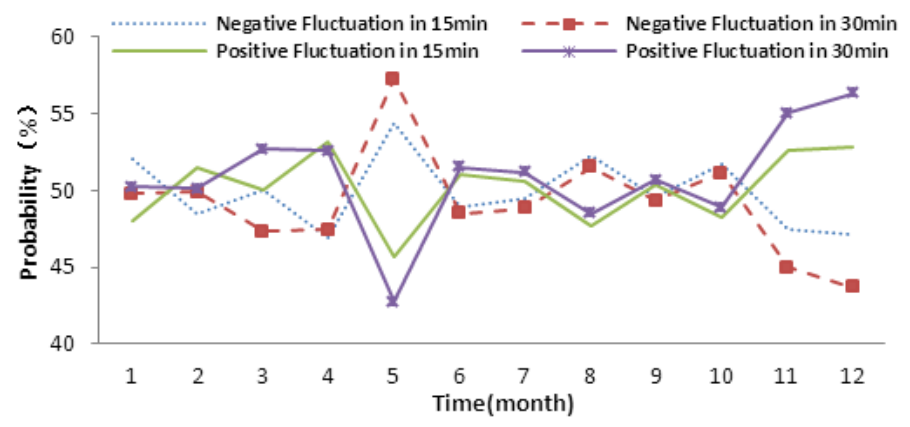

(a)

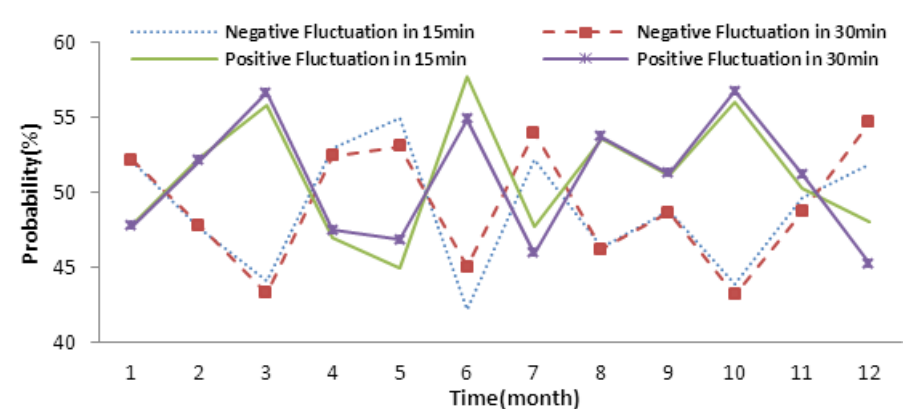

(b)

Figure 7. The probability of wind power appears negative and positive fluctuation in load climbing/lowering period. (a) In load climbing period; (b) In load lowering period.

trends of the active outputs of wind farms are consistent. With Zhenlai wind farm, Hei Yupao wind farm and Mali wind farm, for example, the output curves of this three wind farms among $6^{\text {th }}$ to $13^{\text {th }}$ in February are drawn as Figure 8 and it is obvious that their changing trends show much similarity, so there is a strong correlation between the active outputs of Zhenlai, Hei Yupao and Mali.

Table 1 describes the correction between the active outputs of wind farms in Jilin. Xinfeng wind farm and Wangzi wind farm are respectively located in Siping and Songyuan area. Tongfa wind farm locates in the southern of Baicheng, the other wind farms locates in the northern of Baicheng. Take the Zhenlai as an example, the correlation is 0.01 between the active outputs of Zhenlai and Xinfeng which are the furthest, the correlation increased with the distance between wind farms is reduced, the correlation is 0.82 between the active outputs of Zhenlai and Mali which are the closest.

Based on the original load, a new equivalent load, in which wind power output is regarded as negative load, is formed. The change in the peak-valley difference between the equivalent load and the original load is showed as Figure 9. From the figure we can see that the probability of the equivalent load peak-valley difference is bigger than the original load's by more than $60 \%$. The corresponding probability of peak-valley difference ratio is $70 \%$ and the maximum change can be increased $1000 \mathrm{MW}$. So peak load counter-regulation of wind power in Jilin is obvious and put great pressure on the peak load regulation.

\section{The Impact of Wind Power on Power Grid in Jilin}

\subsection{The Impact of Wind Power on Frequency Regulation}

According to statistics about wind power fluctuation in Jilin, the probability of wind power fluctuation in - $6 \%$ $6 \%$ is $99.55 \%$ in 15 min. Considering by the end of 2012, the installed capacity of wind power in Jilin is 3298 MW and the rate of load change, which caused by wind power fluctuation, is less than $1.02 \%$ every minute, therefore it is unlikely that wind power fluctuation has a significant impact upon frequency regulation in a short timescale. Analysis on the wind power volatility in load climbing and lowering period shows that the probability of wind power negative/positive fluctuation appeared in load climbing/lowering period are both about $50 \%$ in each month. Only a few months, in load climbing/lowering period, wind power have an obviously fluctuation 


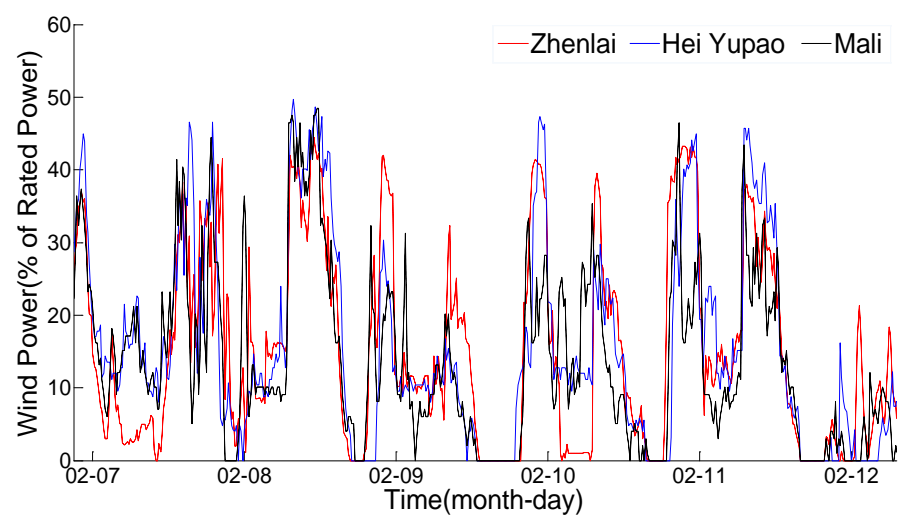

Figure 8. The wind power curves of Zhen Lai, Hei Yupao and Ma Li.

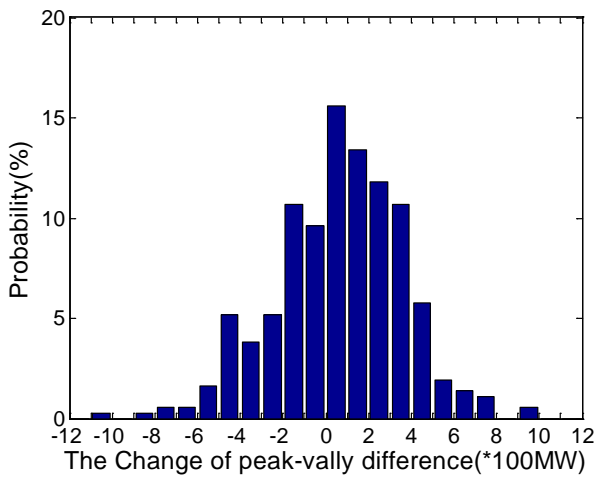

(a)

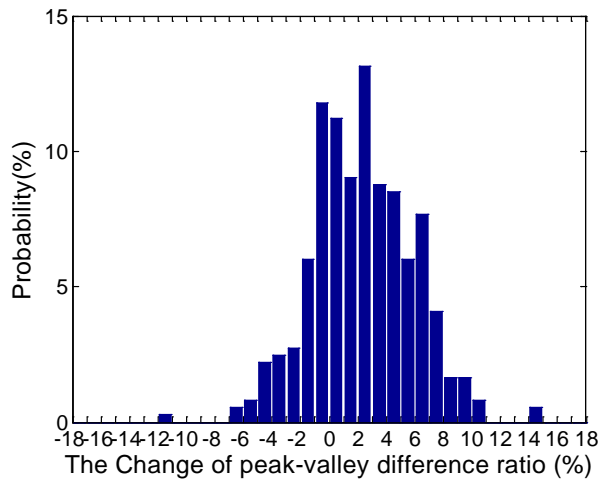

(b)

Figure 9. The change in peak valley difference and peak valley difference ratio between the equivalent load and original load. (a) Peak valley difference; (b) Peak-valley difference ratio.

Table 1. Correlation coefficient between the wind power output of wind farms.

\begin{tabular}{ccccccc}
\hline windfarm & Xinfeng & Wang-zi & Tongfa & Heiyupao & Mali & Zhen-lai \\
\hline Xinfeng & 1 & 0.22 & 0.25 & 0.21 & 0.08 & 0.01 \\
Wang-zi & - & 1 & 0.37 & 0.39 & 0.38 & 0.35 \\
Tongfa & - & - & 1 & 0.52 & 0.52 & 0.49 \\
Heiyupao & - & - & - & 1 & 0.80 & 0.70 \\
Mali & - & - & - & - & - & 0.82 \\
Zhen-lai & - & - & - & - & - & 1 \\
\hline
\end{tabular}

but the magnitude of fluctuation was small in a short timescale, so wind power fluctuation has little impact upon frequency regulation in load climbing/lowering period. In conclusion, when the installed capacity of wind power in Jilin is within certain realms, the requirement of frequency regulation, caused by wind power fluctuation, can be satisfied by the primary/secondary frequency regulation of conventional unit.

\subsection{The Impact of Wind Power on Peak Load Regulation}

According to statistics about the change in the peak-valley difference between the equivalent load and the original load, the probability of the peak-valley difference of the equivalent load is bigger than the original load's is more than $60 \%$ and the maximum change can be increased $1000 \mathrm{MW}$, so peak load counter-regulation of wind power is obvious. In Jilin, the thermal power capacity is a major component of power capacity of directly con- 
trolled generations, the hydro-power proportion is little. The power supply structure of Jilin power system is unreasonable because of lacking of peak-load regulation power sources. Large-scale wind power integration adds to the difficulty of peak regulation. Especially during winter's heating period, in low-load period, it leaves no room for wind power. In high-load period, on the one hand, thermal power units, influenced by factors such as coal, equipment and heating, the power peaking magnitude can't satisfy the peak-shaving requirements of power system, influenced the accommodation of massive wind power. On the other hand, that's because of randomness and intermittence of wind power, according to the cumulative probability distribution of wind power in highload hours (as shown in Figure 3), under the 95\% confidence level, the wind power credible capacity is less than $3 \%$ of the installed capacity. So in such a case, it requires open sufficient capacity of conventional units to assure steady and safety of power system. Since wind power resource conditions and current status of peak-load adjustment of Jilin power grid, first, it requires to speed up the construction of peak-load regulation power sources and equips with a greater capacity of peak-load regulation, and second, day-ahead dispatching plan and intraday balance of electric power and electric quantity should include of wind power, day-ahead dispatching plan should rolling adjust within day, to satisfy the requirements of peak-load regulation with wind power integration, to resolve the contradiction between peak-load regulation and accommodation of wind power.

\subsection{The Impact of Wind Power Concentrated Integration in Baicheng}

Baicheng is the region of wind power concentrated integration, Baicheng power grid is in the terminal of Jilin power grid and weak in network structure. Zhenlai substation is one of nodes in Baicheng that wind power concentrated integration. According to the analysis of the output curves of Zhenlai, Hei Yupao and Mali, all integrated to Zhenlai substation (as shown in Figure 8), it is obvious that the changing trends of their wind power show much similarity, which lead to the total wind power fluctuate wildly and have a big impact on grid, directly affected the stability of power grid. In addition, in Baicheng, there are strong correlations and high simultaneity factor between wind power outputs of wind farms. For now, in Baicheng, the maximum load is $900 \mathrm{MW}$ but the installed capacity of wind power is nearing 2000 MW. So amount of wind power should be outgone. Meanwhile owing to the limits of the power grid structure, it often happens that the transmission lines are nearing to full-loaded when wind power is rich. In the extreme case of wind outgoing cross section approaching steadystate, it has to take measures to curtail wind. The problem of accommodation of wind power in Baicheng is serious. So according to actual conditions of power grid and construction progress of wind farms, the scale of wind power integration should be made a reasonable assessment to ensure the healthy and orderly development of wind power in Jilin.

\section{Conclusions}

The paper aims at analyzing the impact of time-sequence characteristics of wind power on power grid, from the probability distribution characteristics, volatility and correlation of wind power to study wind power time series, then we can get the following main conclusions:

1) Wind power time series in Jilin has the following characteristics: a) Wind power has obviously seasonal characteristic, the monthly utilization hours in Spring and Autumn is the highest. Winter's comes second, Summer's is the lowest. b) The large fluctuation process is last for more than 24 hours and fluctuate wildly, significantly affected dispatching operation of power grid. c) When the distance between wind farms is nearer, the correction between their active outputs is higher, and the volatility is larger. The correlation decreased with the distance between wind farms is increased.

2) When the installed capacity of wind power in Jilin is within certain realms, the requirement of frequency regulation, caused by wind power fluctuation, is low and can be satisfied by the primary/secondary frequency regulation of conventional units. Peak load counter-regulation of wind power in Jilin is obvious, it's requires to speed up the construction of peak-load sources, day-ahead dispatching plan and intraday dispatching plan should include of wind power, to satisfy the requirements of peak-load regulation with wind power integration.

3) Baicheng is the region of wind power concentrated integration, the correlation coefficient between wind power outputs of wind farms that integrated into the same access point is high, the total wind power fluctuate wildly, having a big impact on power grid which is against accommodation of wind power. Meanwhile owing to the limits of network structure and the transmission capacity of wind power, the problem of accommodation of wind power is serious in Baicheng. 


\section{Acknowledgements}

The authors gratefully acknowledge the support of National Key Technology Support Program (2013BAA02B01) and Science and Technology Project of SGCC.

\section{References}

[1] Wang, L.-J., Liao, X.-Z., Gao, Y., et al. (2009) Summarization of Modeling and Prediction of Wind Power Generation. Power System Protection and Control, 37, 118-121.

[2] Tian, C.-Z., Li, Q.-L. and Song, X.-K. (2009) Modeling and Analysis of the Stability for the Power System Considering the Integration of the Wind Farms. Power System Protection and Control, 37, 46-51.

[3] Lu, Z.-X.and Min, Y. (2012) Multiple Time and Spatial Scale Dispatching Techniques of Volatile Energy Generation Based on Power Prediction. Journal of Electric Power Science and Technology, 27, 28-33.

[4] Xiao, C.-Y., Wang, N.-B., Zhi, J., et al. (2010) Power Characteristics of Jiuquan Wind Power Base. Automation of Electric Power Systems, 34, 64-67.

[5] Yang, Z.-L., Zhu, Z.-L., Li, R.-Y., et al. (2010) Analysis on Output Power Characteristics of Jiangsu Coastal Typical Wind Farm. East China Electric Power, 38, 37-40.

[6] Gao, D.B., Li, Q., Jin, Y., Yu, J. and Zhang, J.-N. (2010) Analysis and Research of Operational Characteristics of Wind Power Generation in Northeast Power Grid. Electric Power Technology, 19, 33-37.

[7] Li, J.-N., Qiao, Y., Lu, Z.-X., Li, J. and Xu, F. (2010) Research on Statistical Modeling of Large-Scale Wind Farms Output Fluctuations in Different Special and Temporal Scales. Power System Protection and Control, 40, 7-13.

[8] Hou, Y.-H., Fang, D.-Z., Qi, J., et al. (2010) Analysis on Active Power Fluctuation Characteristics of Large-Scale Grid-Connected Wind Farm and Generation Scheduling Simulation under Different Capacity Power Injected From Wind Farms into Power Grid. Power System Technology, 40, 7-13.

[9] Kang, C.-Q., Xia, Q.and Xu, W. (2011) Uncertainty Analysis in Power Systems. Sciences Press, Beijing.

[10] Hannele, H. (2004) The Impact of Large Scale Wind Farms Integration in Nordic Countries. Ph.D. Thesis, Helsinki University.

[11] Wang, Z., Wang, W.S., Liu, C. and Feng, S.L. (2013) Uncertainty Estimation of Wind Power Prediction Result Based on Wind Process Method. Power System Technology, 37, 242-247.

[12] Wang, Z. (2012) Uncertainty Estimation of Wind Power Forecasting Result Based on Wind Process and Non- Parametric Regression. Master’s Thesis, CEPRI, Beijing. 